\title{
Serotonin enhances solitariness in phase transition of the migratory locust
}

\author{
Xiaojiao Guo ${ }^{1+}$, Zongyuan $\mathrm{Ma}^{2+}$ and Le Kang ${ }^{1,2 *}$ \\ ' State Key Laboratory of Integrated Management of Pest Insects and Rodents, Institute of Zoology, Chinese Academy of Sciences, Beijing, China \\ ${ }^{2}$ Beijing Institutes of Life Sciences, Chinese Academy of Sciences, Beijing, China
}

\author{
Edited by: \\ Martin Giurfa, Centre National de la \\ Recherche Scientifi que - Université \\ Paul Sabatier-Toulouse III, France \\ Reviewed by: \\ Raphael Jeanson, University of \\ Toulouse, France \\ Mathieu Lihoreau, The University of \\ Sydney, Australia \\ *Correspondence: \\ Le Kang, State Key Laboratory of \\ Integrated Management of Pest \\ Insects and Rodents, Institute of \\ Zoology, Chinese Academy of \\ Sciences, 1 Beichen West Road, \\ Chaoyang District, Beijing 100101, \\ China \\ e-mail: Ikang@ioz.ac.cn \\ these authors have contributed \\ equally to this work.
}

The behavioral plasticity of locusts is a striking trait presented during the reversible phase transition between solitary and gregarious individuals. However, the results of serotonin as a neurotransmitter from the migratory locust Locusta migratoria in phase transition showed an alternative profile compared to the results from the desert locust Schistocerca gregaria. In this study, we investigated the roles of serotonin in the brain during the phase change of the migratory locust. During the isolation of gregarious nymphs, the concentration of serotonin in the brain increased significantly, whereas serotonin receptors (i.e., 5-HT, $5-H T_{2}$, and $5-H T_{7}$ ) we identified here showed invariable expression patterns. Pharmacological intervention showed that serotonin injection in the brain of gregarious nymphs did not induced the behavioral change toward solitariness, but injection of this chemical in isolated gregarious nymphs accelerated the behavioral change from gregarious to solitary phase. During the crowding of solitary nymphs, the concentration of serotonin in the brain remained unchanged, whereas $5-H T_{2}$ increased after $1 \mathrm{~h}$ of crowding and maintained stable expression level thereafter. Activation of serotonin-5- $\mathrm{HT}_{2}$ signaling with a pharmaceutical agonist inhibited the gregariousness of solitary nymphs in crowding treatment. These results indicate that the fluctuations of serotonin content and $5-H T_{2}$ expression are results of locust phase change. Overall, this study demonstrates that serotonin enhances the solitariness of the gregarious locusts. Serotonin may regulate the withdrawal-like behavioral pattern displayed during locust phase change and this mechanism is conserved in different locust species.

Keywords: neurotransmitter, serotonin receptors, RNA interference, phenotypic plasticity, gregariousness, isolation, Locusta migratoria, behavior

\section{INTRODUCTION}

Phase polyphenism in locusts, a striking example of phenotypic plasticity, is important in evolution and adaptation (WestEberhard, 2003; Pener and Simpson, 2009; Moczek, 2010). The migratory locust (Locusta migratoria) exhibits solitary and gregarious phases with phase-specific behavioral characteristics. Solitary individuals are inactive and exhibit repulsive behavior, whereas gregarious ones are active, show upright posture, and attract each other (Uvarov, 1966; Pener and Simpson, 2009; Burrows et al., 2011). Previous studies have shown that the patchy distribution of food resources concentrates locusts on the small scale, and the increase in population density forces solitary individuals to contact with each other and causes gregarization (Collett et al., 1998; Despland et al., 2000). The change in population density results in the reversible phase transition between solitary and gregarious phases (Despland, 2001; Guo et al., 2011). This behavioral pattern makes locusts aggregate with one another to form enormous swarms that result in severe economic and agriculture losses (Tanaka and Zhu, 2005; Brader et al., 2006). However, the mechanisms in controlling the formation of locust aggregation through new behavioral regulators are not fully characterized.

Great progresses have been made in revealing the genetic and metabolic mechanisms underlying the regulation of behavioral phase changes (Kang et al., 2004; Wu et al., 2012). Many neurotransmitters have been documented to play important roles in regulating behavioral phase changes in locusts (Anstey et al., 2009; Chen et al., 2010; Ma et al., 2011). Dopamine has been proved to regulate the gregariousness of solitary nymphs in the migratory locust (Ma et al., 2011). Our functional insights into the role of serotonin arose through the recent contradictory discovery of this chemical as a regulator of phase change in the migratory locust and desert locust (Schistocerca gregaria). In the migratory locust, unlike the clear function of dopamine in inducing and maintaining gregarious behavior (Ma et al., 2011), we found that the injection of serotonin in solitary nymphs partially induced gregarious-like behavior. However, long-term injection of serotonin precursor 5-Hydroxytryptophan (5-HTP) and exposure to crowding inhibited performance of gregarious behavior (Ma et al., 2011). In the desert locust, serotonin has been found to be necessary and sufficient to induce gregarious behavior (Anstey et al., 2009), but no genetic and molecular evidence has been reported. Moreover, another study shows that serotonin is not involved in attraction/avoidance behavior, which is one of the most important behavioral traits in aggregation (Tanaka and Nishide, 2012). Collectively, the results regarding the role of serotonin in regulating phase change from different locust species and different laboratories are contradictory. 
When crowded with other locusts, solitary individuals are subjected to visual, olfactory and mechanosensory stimuli from their gregarious conspecifics and shift their behavior toward the gregarious phase. The brain and thoracic ganglia in the central nervous system signal olfactory/visual and mechanosensory stimuli, respectively (Simpson et al., 2001; Rogers et al., 2003; Guo et al., 2011). In the desert locust, the confirmation of serotonin function in phase change focused on the tissue of thoracic ganglia (Anstey et al., 2009). Although the insect thoracic ganglia acts as the central pattern generator to regulate the locomotion circadian rhythms and mechanosensory stimuli (Berkowitz and Laurent, 1996), the ability of the thoracic ganglia to monitor movement and other activities depends on the instruction of the brain through descending pathways (Delcomyn, 1999; Schaefer and Ritzmann, 2001). Therefore, knowing how serotonin in the brain modulates behavioral transition of migratory locusts is necessary for us to comprehensively understand the role of serotonin in the phase change of locusts.

In this study, we measured serotonin levels in the brain over a time course of crowding and isolation to determine whether serotonin in the brain regulates phase change. In addition, we cloned serotonin receptors and studied the expression of these receptors during phase change to determine whether serotonin receptors mediate behavioral phase change in the migratory locust. The results showed that serotonin levels in brains of gregarious nymphs significantly increased during isolation, and injection of serotonin into the brain accelerated the behavioral transition from the gregarious to solitary phase in isolated gregarious individuals. Although we found that the expression pattern of the $5-H_{2}$ receptor subtype increased in the brain during crowding, activating serotonin-5- $\mathrm{HT}_{2}$ signaling with a pharmaceutical agonist inhibited the gregarious behavior of solitary locusts. In addition, inactivation of this signaling via RNA interference (RNAi) had no effect on the gregariousness of locusts.

\section{MATERIALS AND METHODS ANIMALS}

The migratory locusts used in this study were from colonies maintained in the Institute of Zoology, Chinese Academy of Sciences, Beijing, China. Gregarious nymphs were cultured in large boxes $\left(40 \times 40 \times 40 \mathrm{~cm}^{3}\right)$ at a density of $500-1000$ insects per container. Solitary nymphs were obtained from the gregarious colony and cultured alone in white metal boxes $\left(10 \times 10 \times 25 \mathrm{~cm}^{3}\right)$ supplied with charcoal-filtered compressed air for at least three generations before experimentation. The gregarious and solitary colonies were maintained under a $14 \mathrm{~h}$ light $/ 10 \mathrm{~h}$ dark cycle at $30 \pm 2^{\circ} \mathrm{C}$ and fed on fresh wheat seedlings and bran (Kang et al., 2004).

\section{HIGH-PERFORMANCE LIOUID CHROMATOGRAPHY (HPLC) WITH ELECTROCHEMICAL DETECTION (ECD)}

Serotonin in the brains (without optic lobe) of the migratory locust was quantified with reverse-phase high performance liquid chromatography (HPLC) with electrochemical detection (ECD). The brain tissues of the fourth-stadium solitary, gregarious, crowded, and isolated nymphs were immediately dissected and stored in liquid nitrogen. Ten brains per sample were homogenized using a mortar and pestle pre-cold with liquid nitrogen. Pulverized brain tissue was transferred to $1.5 \mathrm{ml}$ Eppendorf tubes (Eppendorf International, Hamburg, Germany), and then lysed in $400 \mu \mathrm{L}$ ice-cold $0.1 \mathrm{M}$ perchloric acid (Sigma-Aldrich) on ice for $10 \mathrm{~min}$. The homogenates were centrifuged at $14,000 \times \mathrm{g}$ for $10 \mathrm{~min}$ at $4^{\circ} \mathrm{C}$. The supernatants were passed through $0.45 \mu \mathrm{m}$ filters (Millipore Corporation, Billerica, MA, USA), transferred to new Eppendorf tubes, and stored at $-80^{\circ} \mathrm{C}$ until HPLC-ECD analysis. Forty $\mu \mathrm{L}$ supernatants were automatically loaded onto a quaternary low-pressure pump (Waters Corporation, e2695, Milford, MA, USA) with a C18 reverse phase column (Atalantis ${ }^{\mathrm{TM}}$ $\mathrm{dC1}$, $2.1 \times 150 \mathrm{~mm}, 3 \mu \mathrm{m}$, Waters Corporation). The electrode potential in the electrochemical detector was set at $800 \mathrm{mV}$. The mobile phase $(\mathrm{pH} 3.00)$ was composed of $7 \%$ acetonitrile (J\&K Scientific Ltd., Beijing, China), $90 \mathrm{mM}$ monobasic phosphate sodium (Sigma-Aldrich), $50 \mathrm{mM}$ citric acid (SigmaAldrich), $2 \mathrm{mM}$ octanesulfonic acid (J\&K Scientific Ltd., Beijing, China), $2 \mathrm{mM} \mathrm{NaCl}$ (Sigma-Aldrich), and $50 \mu \mathrm{M}$ EDTA (SigmaAldrich). The flow rate was adjusted to $0.25 \mathrm{~mL} \mathrm{~min}^{-1}$, and the temperature was set at $35^{\circ} \mathrm{C}$. Data analysis was performed using Empower software (Waters Corporation). The serotonin levels were quantified by referring to external standards. The standard curve was generated with serial dilutions of standard solution containing serotonin (Sigma-Aldrich).

\section{PHYLOGENETIC ANALYSIS OF SEROTONIN RECEPTORS}

The sequences of serotonin receptors in the migratory locust were cloned by referring to putative sequences in the wholegenome database of Locusta migratoria. The other amino-acid sequences of serotonin receptors used for phylogenetic analysis were identified in the NCBI databases. To classify the subtypes of serotonin receptors, multiple sequence alignments of these insect serotonin receptors were performed with Clustal $\mathrm{W}$ and curated in MEGA 5.34 (Tamura et al., 2011). Neighbor-joining analysis was performed in MEGA 5 with bootstrapping 1000 replicates. GenBank accession numbers of protein sequences used were as follows: Antheraea 5- $\mathrm{HT}_{1 \mathrm{~A}}$, ABY85410; Antheraea 5- $\mathrm{HT}_{1 \mathrm{~B}}$,

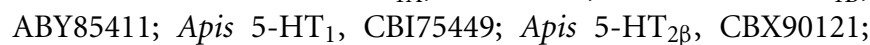
Apis 5- $\mathrm{HT}_{2 \alpha}$, CBX90120; Apis 5- $\mathrm{HT}_{7}, \mathrm{CAJ} 28210$; Bombyx 5HT, NP_001037502; Danaus 5-HT, EHJ69998; Danaus 5-HT, EHJ73524; Drosophila 5-HT $1 \mathrm{~A}, \mathrm{NP}_{4} 476802$; Drosophila $5-\mathrm{HT}_{1 \mathrm{~B}}$, NP_523789; Drosophila 5- $\mathrm{HT}_{7}, \mathrm{NP} \_524599 ;$ Drosophila 5- $\mathrm{HT}_{2 \beta}$, NP_649806; Drosophila 5- $\mathrm{HT}_{2 \mathrm{~B}}$, NP_730859; Gryllus 5- $\mathrm{HT}_{7}$,

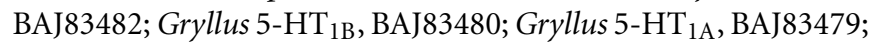
Gryllus 5-HT $2 \alpha$, BAJ83481; Heliothis 5-HT, CAA64863; Manduca 5- $\mathrm{HT}_{1 \mathrm{~A}}, \mathrm{ABI} 33826$; Manduca 5- $\mathrm{HT}_{1 \mathrm{~B}}, \mathrm{ABI} 33827$; Papilio 5-HT, BAD72868; Periplaneta 5- $\mathrm{HT}_{1}, \mathrm{CAX65666;}$ Tribolium 5- $\mathrm{HT}_{7}$, XP_966577; Tribolium 5-HT, XP_967449; Tribolium 5- $\mathrm{HT}_{2 a}$, XP_972327.

\section{EXPERIMENTAL SAMPLES ISOLATION OF GREGARIOUS LOCUSTS}

The fourth-stadium gregarious nymphs were isolated and individually reared as solitary nymphs. After $1,4,16$, or $32 \mathrm{~h}$ of isolation, the brains of isolated nymphs were dissected and immediately placed in RNAlater Solution (Ambion, Austin, 
Texas, USA) for qRT-PCR analysis. The brains of gregarious nymphs maintained in groups were sampled as the control group. To avoid the effects of circadian rhythm on phenotype of gregarious nymphs, all insects were sampled at the same time point for four biological replicates, and equal numbers of male and female insects were sampled per biological replicate.

\section{CROWDING OF SOLITARY LOCUSTS}

Ten solitary nymphs at the fourth stadium were introduced into an optic perplex-made box $\left(10 \times 10 \times 10 \mathrm{~cm}^{3}\right)$ and allowed to live with the gregarious nymphs at the same stadium. After staying with the stimulus group and crowding for $1,4,16$, or $32 \mathrm{~h}$, the brains of the crowded nymphs were dissected and immediately placed in RNAlater Solution for subsequent qRT-PCR analysis. The brains of solitary nymphs were sampled as the control group. All insects were sampled at the same time point for eight biological replicates, and equal numbers of male and female insects were sampled per biological replicate.

\section{RNA PREPARATION}

To eliminate the heterogeneity of different samples, total RNA was extracted from the brain tissues of controlled and treated nymphs. The brains were transferred into the lysis buffer and total RNA was extracted following the protocol of an RNAeasy mini kit (QIAGEN, Hilden, Germany).

\section{qRT-PCR}

For analysis of the transcript of the three receptors, $2 \mu \mathrm{g}$ total RNA was reverse-transcribed using MMLV reverse transcriptase (Promega, Madison, USA) following the manufacturer's instructions. PCR reactions were performed in a $20 \mu \mathrm{l}$ volume and the final concentration of the primers was $250 \mathrm{nM}$. PCR amplification was conducted using RealMaster-Mix (SYBR Green) kit (Tiangen, Beijing, China), initiated with a 2 min incubation at $95^{\circ} \mathrm{C}$, followed by 40 cycles of $20 \mathrm{~s}$ at $95^{\circ} \mathrm{C}, 20 \mathrm{~s}$ at $58^{\circ} \mathrm{C}$ and $20 \mathrm{~s}$ at $68^{\circ} \mathrm{C}$. Four to eight biological replicates were performed for each sample. The expression of $5-H T_{1}, 5-H T_{2}, 5-H T_{7}$ and the housekeeping gene ribosomal protein 49 (RP49) were detected using a Roche LightCycler 480. The standard curves for target genes $\left(5-H T_{1}, 5-H T_{2}, 5-H T_{7}\right)$ and reference genes (RP49) were generated with serial $(10 \times)$ dilutions of plasmids. Efficiency of qRT-PCR and correlation coefficients were determined for the primers of each gene. We normalized all relative expression levels of three genes against the reference gene. Melting curve analysis was performed to confirm the specificity of amplification and all amplification products revealed a single melting peak. All PCR products were sequenced to confirm their identity before qRT-PCR experiments. The primers for qRT-PCR are listed in Table 1.

\section{BEHAVIORAL PHARMACOLOGY IN GREGARIOUS NYMPHS}

To clearly determine the role of serotonin in regulating phase change of locusts, we chose the central position between the paired compound eyes to inject serotonin $(5 \mathrm{mM} \times 3 \mu \mathrm{L}$; SigmaAldrich) into the anterior of the locust brain using a microsyringe with a depth of $1-2 \mathrm{~mm}$. We made sure the tip of the micro-syringe was injected from ventral to dorsal direction of
Table 1 | Primer sequences for qRT-PCR.

\begin{tabular}{lll}
\hline Genes & Forward primer $\left(\mathbf{5}^{\prime} \mathbf{-} \mathbf{3}^{\prime}\right)$ & Reverse primer $\left(\mathbf{5}^{\prime} \mathbf{-} \mathbf{3}^{\prime} \mathbf{)}\right.$ \\
\hline $5-H T_{1}$ & TGGGCAACGAGCACGAGGA & GCTCGTTGCCCAGGATGAG \\
$5-H T_{2}$ & CCGCGTCACGCTCAAGATC & AGGCTCATGGCGATGGAGA \\
$5-H T_{7}$ & AGTGCCAGGTGTGCCAGA & GTCGCCCTACATCTTCCT \\
$R P 49$ & CGCTACAAGAAGCTTAAGAGGTCAT & CCTACGGCGCACTCTGTTG
\end{tabular}

the locust head to avoid damaging the brain. The fourth-stadium gregarious nymphs injected with serotonin were immediately isolated for 15 or $30 \mathrm{~min}$ before the behavior assay. The control group received the same volume of saline for the behavioral assay.

Ketanserin and methiothepin (Sigma-Aldrich), antagonists of serotonin receptors, were applied as a cocktail to cover the range of possible pharmacological types of serotonin receptors in locusts as described in detail by Anstey et al. (2009). The antagonist cocktail $(5 \mathrm{mM} \times 3 \mu \mathrm{L})$ was injected into the head cavities of fourth-stadium gregarious nymphs in the same manner as serotonin. Behavior was assayed 15 or $30 \mathrm{~min}$ after isolation. The control group received the same volume of saline for the behavioral assay.

\section{BEHAVIORAL PHARMACOLOGY IN SOLITARY NYMPHS}

To analyze the role of $5-\mathrm{HT}_{2}$ in crowding of the migratory locust, ( \pm )-1-(2,5-Dimethoxy-4-iodophenyl)-2-aminopropane hydrochloride [( \pm -DOI] $(5 \mathrm{mM} \times 70 \mathrm{~nL}$; Sigma-Aldrich $), a$ $5-\mathrm{HT}_{2}$ agonist (Colas et al., 1995; Johnson et al., 2009), was injected into the brains of fourth-stadium solitary nymphs $1 \mathrm{~h}$ before the behavioral assay. Briefly, the fourth-stadium nymphs were placed in a Kopf stereotaxic frame specially adapted for locust surgery. A midline incision was cut in the central position between the paired compound eyes using Nevis scissors to expose the underlying brain. All injections were performed under anatomical lens using a NANOLITER injector 2000 (World Precision Instruments, Sarasota, FL, USA) with a glass micropipette tip. The fourth-stadium solitary nymphs were put back into the solitary-rearing cages or were introduced into an optic perplex-made box $\left(10 \times 10 \times 10 \mathrm{~cm}^{3}\right)$ and allowed to live with the gregarious nymphs at the same stadium for $1,4,16$, or $32 \mathrm{~h}$. Again, all control groups received the same volume of saline for the behavioral assay.

\section{RNAi AND BEHAVIORAL ASSAY IN SOLITARY NYMPHS}

Double-strand RNA (dsRNA) of green fluorescent protein (GFP) and $5-\mathrm{HT}_{2}$ were prepared using the T7 RiboMAX Express RNAi system (Promega, Madison, USA) according to the manufacturer's instructions. The primers for dsRNA preparation are listed in Table 2. To find the optimal amount of dsRNA for RNAi injection and behavioral assay, we directly injected 12,24 , or $36 \mathrm{ng}$ of dsRNA into the brains of fourth-stadium solitary nymphs as described above. After dsRNA injection, the solitary nymphs lived alone in solitary-rearing cages, and the effects of RNAi on the relative mRNA level were detected by qRT-PCR after $72 \mathrm{~h}$. After then, the dsRNA-injected solitary nymphs were directly assayed or moved to the environment with gregarious nymphs 
Table 2 | Primer sequences for RNAi.

\begin{tabular}{lll}
\hline Genes & Forward primer $\left(\mathbf{5}^{\prime} \mathbf{-} \mathbf{3}^{\prime}\right)$ & Reverse primer $\left(\mathbf{5}^{\prime} \mathbf{-} \mathbf{3}^{\prime}\right)$ \\
\hline $5-H T_{2}$ & CTTCTTCGTGCTCAACCTG & GGAATGTATGAGGTCGTGAG \\
GFP & CACAAGTTCAGCGTGTCCG & GTTCACCTTGATGCCGTTC \\
\hline
\end{tabular}

$\left(10 \times 10 \times 10 \mathrm{~cm}^{3}\right)$ and crowded for $1,4,16$, or $32 \mathrm{~h}$, respectively, before behavioral assay.

\section{BEHAVIORAL ASSAY IN ARENA}

We used the EthoVision system (Noldus Inc. Wageningen, the Netherlands) for video recording and data extraction. The arena behavior assay was performed in a rectangular arena $(40 \times 30 \times$ $\left.10 \mathrm{~cm}^{3}\right)$. The wall of the arena is opaque plastic and the top is clear. One of the separated chambers $\left(7.5 \times 30 \times 10 \mathrm{~cm}^{3}\right)$ contained 20 fourth-stadium gregarious locusts as the stimulus group, and the other end of the chamber with the same dimensions is left empty. Both ends of the chamber were illuminated equally to prevent the formation of mirror images. The floor of the open arena was covered with filter paper during the behavior assay. The locust nymphs were gently transferred by a tunnel to the arena. Every insect was recorded for $6 \mathrm{~min}$ and examined only once (Roessingh et al., 1993; Anstey et al., 2009; Guo et al., 2011; Ma et al., 2011).

To measure and evaluate the phase state of the fourth-stadium solitary and gregarious nymphs, we constructed a binary logistic regression model in SPSS 15.0 to measure and quantify their behavioral phenotype (Ma et al., 2011). Eleven different behavioral parameters were expressed as a mixture of behavioral or categorical markers acquired as follows: entry frequency in the stimulus area (EFISA, stimulus area was defined as $25 \%$ of the arena closest to the stimulus group), latency of first occurrence in stimulus area (LFOISA), total duration in the area close to the arena wall (TDCW), entry frequency in the area close to the arena wall (EFCW), entry frequency in the region opposite the stimulus area (EFIOSA, the opposite of the stimulus area was defined as $25 \%$ of the arena at the opposite end of the stimulus group), latency of first occurrence opposite the stimulus area (LFOIOSA), mean distance to the stimulus group (MDTSG), total distance moved (TDM), total duration of movement (TDMV) as well as frequency of movement (FOM) and attraction index (AI, AI stands for the extent of tested animals attracted by the stimulus group. $\mathrm{AI}=$ total duration in stimulus area-total duration in opposite area). In total we measured 100 solitary nymphs and 100 gregarious nymphs at the fourth stadium for extraction of behavioral data. A forward stepwise approach was applied to build the logistic regression model by using the untransformed data of these 11 behavioral parameters. The building process was finished when no more improvement occurred by adding more behavior variables. The independent variables in the logistic regression model were closely correlated with the significant level of their regression coefficient $\beta$ in the Wald test. The behavioral parameters of this model were adjusted until the regression model discriminated the two phases at the optimum level according to the following equation: $\mathrm{P}-\mathrm{sol}=\mathrm{e} \eta /(1+\mathrm{e \eta})$, where $\eta=\beta 0+\beta 1 \cdot \mathrm{X} 1+\beta 2 \cdot \mathrm{X} 2+\cdots+\beta \mathrm{k} \cdot \mathrm{Xk}, \mathrm{X} 1, \mathrm{X} 2, \ldots, \mathrm{Xk}$ are
Table 3 | Behavioral variables retained in the best-fitting logistic regression model obtained from the fourth-stadium solitary and gregarious nymphs.

\begin{tabular}{lllllll}
\hline Parameters in equation & $\boldsymbol{\beta}$ & $\boldsymbol{S E}$ & Wald & $\boldsymbol{d f}$ & Sig. & $\operatorname{Exp}(\boldsymbol{\beta})$ \\
\hline TDM & -0.016 & 0.004 & 14.286 & 1 & 0.000 & 0.984 \\
FOM & -0.172 & 0.073 & 5.494 & 1 & 0.019 & 0.842 \\
Al & -0.005 & 0.001 & 20.571 & 1 & 0.000 & 0.995 \\
Constant & 2.361 & 0.353 & 44.773 & 1 & 0.000 & 10.600
\end{tabular}

This table indicates the significance levels of the individual model parameter for the behavioral discrimination of the locust nymphs. Abbreviations: TDM, total distance moved; FOM, frequency of movement; Al, attraction index.

the behavioral covariates. P-sol is the probability that the nymphs should be regarded as a member of the solitary phase population, with a value ranging from 1 to 0 , where 1 means that individuals display solitary behavior and 0 indicates that individuals display gregarious behavior (Table 3 ). The most robust indicators of the phase state were retained in the model. This model shares similar features with previous regression models used for binary discrimination of solitary and gregarious locusts (Roessingh et al., 1993; Anstey et al., 2009; Guo et al., 2011; Ma et al., 2011).

\section{STATISTICAL ANALYSIS}

Expression levels of serotonin receptors between gregarious and solitary locusts were analyzed by the Student's $t$-test. Serotonin content and expression levels of serotonin receptors over a time course of crowding and isolation were analyzed by one-way analysis of variance (ANOVA). The serotonin content and expression levels of receptors were expressed as the mean \pm standard error of the mean (SEM). Behavioral data were analyzed by the Mann-Whitney $U$-test because of the non-normal distribution characteristics. Differences were considered significant at $p<0.05$. The probabilistic metric of solitariness (P-sol) is presented as the median value. All the statistics were analyzed using SPSS 15.0 (SPSS Inc., Chicago, IL, USA).

\section{RESULTS}

\section{CHANGES IN SEROTONIN CONTENT DURING THE PHASE CHANGE OF LOCUSTS}

To confirm whether serotonin regulated behavioral differences between solitary and gregarious phase, we measured serotonin levels in the brains of solitary and gregarious nymphs and found no difference between the two phases of the migratory locust ( $\mathrm{Ma}$ et al., 2011). To explore the role of serotonin in the phase change of the locusts, we first analyzed the fluctuation of serotonin levels over a time course of crowding and isolation to examine the causal relationship of serotonin with phase change. Results revealed that the serotonin level in the brain did not change during the crowding of the solitary nymphs, but the level of serotonin increased during the isolation of gregarious nymphs (Figures 1A,B). These results indicate that changes in serotonin levels in the brain are associated with the solitariness of the gregarious nymphs. 


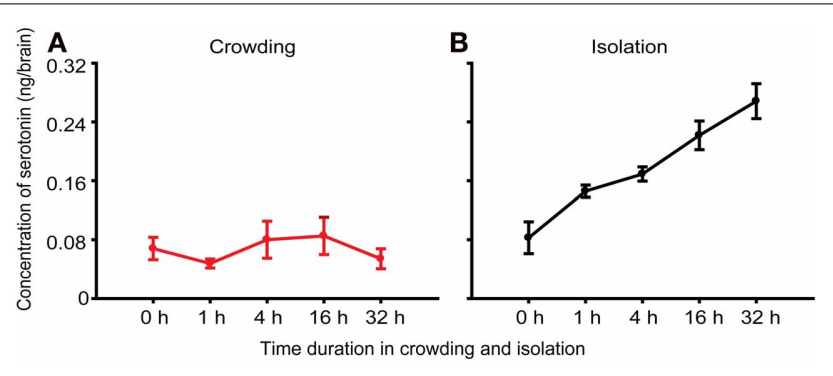

FIGURE 1 | Concentration of serotonin in brains of the migratory locust. (A) Concentration of serotonin in the brains of solitary nymphs subjected to crowding [One-way ANOVA, $F_{(4,35)}=0.529, P=0.753$ ]. (B) Concentration of serotonin in the brains of gregarious nymphs subjected to isolation [One-way ANOVA, $F_{(4,35)}=40.890, P<0.001$ ]. The data represent mean values and error bars represent SEM.

\section{AMINO ACID SEQUENCE ALIGNMENT AND A PHYLOGENETIC ANALYSIS OF SEROTONIN RECEPTORS}

G protein-coupled receptor pathways regulated by neurotransmitters and neuromodulators have been suggested to regulate the phase change of locusts (Chen et al., 2010). As a ligand of G protein-coupled receptors, serotonin controls diverse behaviors in animals (Nichols and Nichols, 2008; Berg and Clarke, 2009). To clone serotonin receptors and discover their roles in phase change, we first collected the putative receptor gene sequences in the whole-genome database of Locusta migratoria using a BLAST search. Referring to these putative sequences, we cloned the partial sequences of three orthologous genes $\left(5-\mathrm{HT}_{1}, 5-\mathrm{HT}_{2}\right.$, and $5-H T_{7}$ ) from the locust brain, and the cDNA fragment length of these three receptors were 753,585 , and $315 \mathrm{bp}$, respectively. To validate and classify the subtypes of serotonin receptors, we performed a phylogenetic analysis using MEGA5.34 (Tamura et al., 2011). The result showed that the three orthologous receptors belonged to the three insect serotonin receptors families (Figure 2). The conserved transmembrane (TM) segments of serotonin receptors were analyzed by the TMHMM Server 2.0 (Sonnhammer et al., 1998). The partial fragment of 5-HT 1 receptors encoded four TM segments that corresponded to the first four GPCR TM segments (TM1-TM4 in Figure 3A), whereas the fragment of $5-\mathrm{HT}_{2}$ receptors included the five TM segments that corresponded to the first to the fifth GPCR TM segments (TM1TM5 in Figure 3B). Moreover, the three TM regions encoded by the partial sequence of $5-\mathrm{HT}_{7}$ were the first to third GPCR TM segments (TM1-TM3 in Figure 3C).

\section{EXPRESSION PATTERNS OF SEROTONIN RECEPTORS DURING THE PHASE CHANGE OF LOCUSTS}

To determine the role of serotonin receptors in regulating behavioral differences between two phases, we detected the expression of the three serotonin receptors $5-H T_{1}, 5-H T_{2}$, and $5-H T_{7}$ in the brains of solitary and gregarious individuals. The three receptors did not show differential expression in fourth-stadium solitary and gregarious nymphs (Figures 4A-C).

To determine the causal relationship of serotonin receptors in regulating behavioral phase change, we detected the expression patterns of the three serotonin receptors during phase change of

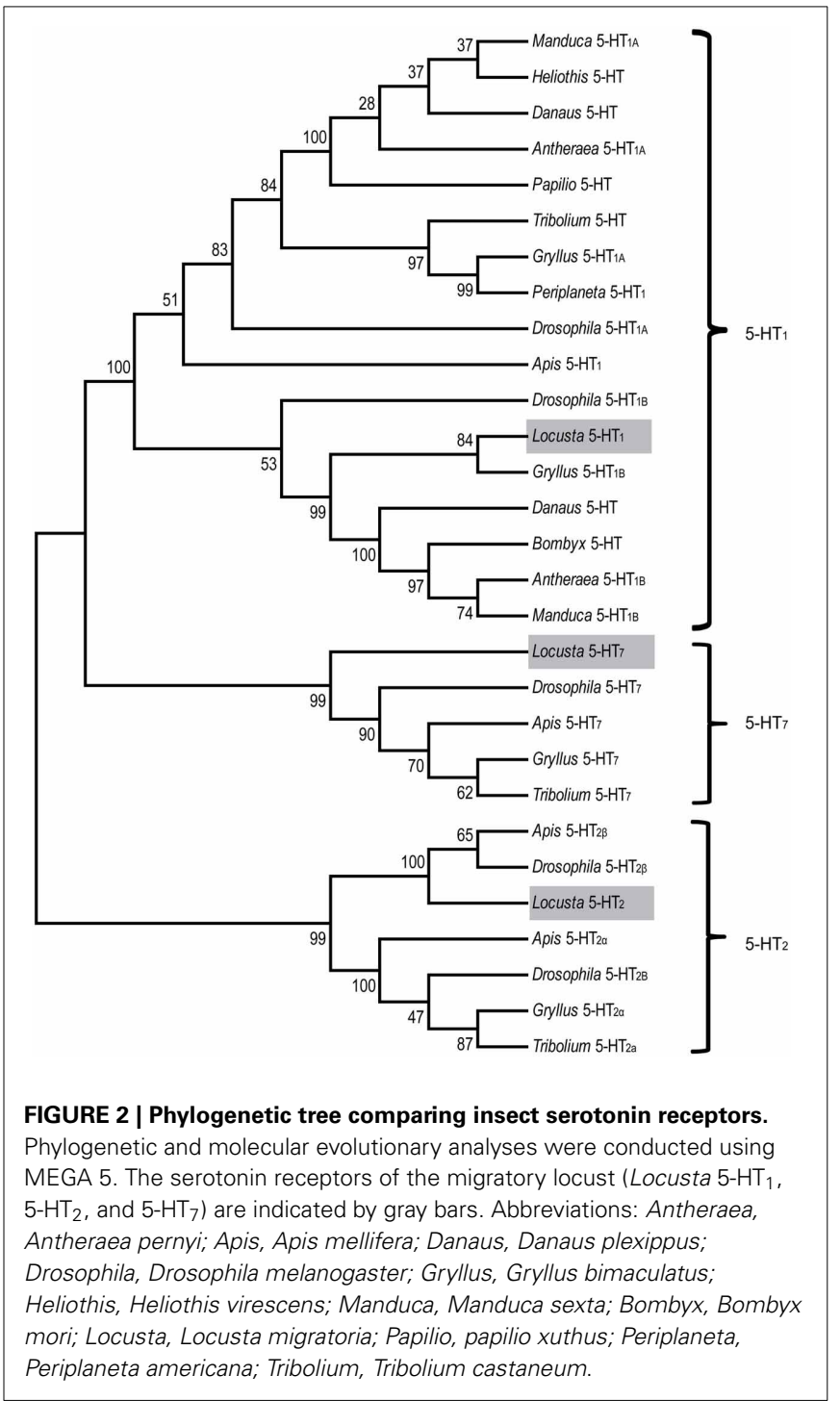

locusts. In the time course of crowding in solitary nymphs, we found that $5-\mathrm{HT}_{2}$ was up-regulated after $1 \mathrm{~h}$ of crowding and remained stable thereafter (Figure 4E). The receptors 5-HT $\mathrm{T}_{1}$ and $5-H T_{7}$ were not differentially expressed over the time course of crowding (Figures 4D,F). In addition, the expression level of the three receptors did not change over the time course of isolation (Figures 4G-I). Thus, 5- $\mathrm{HT}_{2}$ may respond to the gregariousness of solitary nymphs.

\section{ROLE OF SEROTONIN IN THE ISOLATION OF GREGARIOUS NYMPHS}

Given the increase of the serotonin levels with behavioral changes over the time course of isolation, we hypothesized that serotonin played a role in the solitariness of gregarious nymphs. To validate this assumption, we injected different doses of serotonin into the head cavities of fourth-stadium gregarious nymphs to optimize serotonin concentration. Behavioral assay revealed that $5 \mathrm{mM}$ and $20 \mathrm{mM}$ serotonin did not affect the behavioral state of gregarious nymphs (Mann-Whitney $U$-test, $U=468, P=0.172$ for $5 \mathrm{mM}$; $U=609, P=0.404$ for $20 \mathrm{mM}$ ) (Figures $5 \mathrm{~A}-\mathrm{C}$ ). Subsequently, 
A

Dm 5-HT1A 1

$\mathrm{Pa} 5-\mathrm{HT}_{1 \mathrm{~A}} 1$

$\operatorname{Tm} 5-\mathrm{HT}_{1}$

Lm 5-HT1

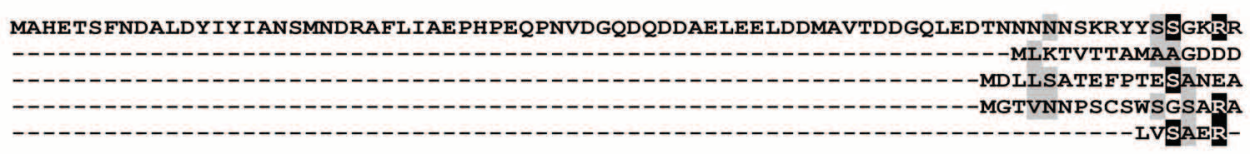

Dm 5-HT1A 81 ADFIGSLALKPPPTDVNTTTTTAGSPLATAALAAAAASASVAAAAARITAKAAHRALTTKQDATSSPASSPALQLIDMDN

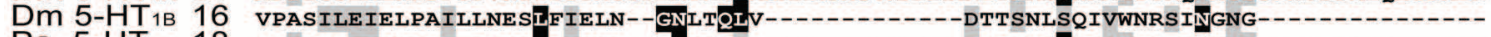

Pa 5-HT1A 18 EEYPDEQLTVKPLYDTVKLTVAEKPSDNDVFIQASEEDEVLTDLYMDDPFTTAASSLIANNSPTSN-----LSVYFEDIIV

Tm 5-HT 18 TIFVIILPAATSATSSGRLIIGSVQTGNNPQLN-----------YPNFLNSADLYHFPGAENATS-----METLYEPWNC

Lm 5-HT 16 --STVMELFGGVVVLWRGLFESMSVIGNCSQPG----

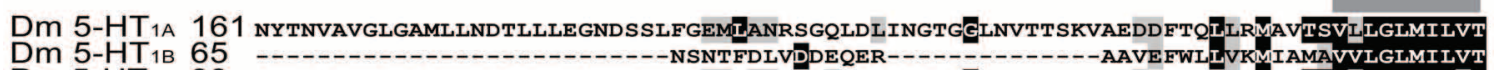

$\mathrm{Pa}$ 5-HT1A 93 GRVACNTTINGSTVYSSSILECYNSTFIGDIFSNASGNGSAIGGRGGD--------EPLTDVILMGVTSVILGLMILII

Tm 5-HT ${ }_{1} 82$ TKLPCN-------------FENETLAHNDTNDTLSDATRG---------EPLADLILMGFLSVVLGLMILVT

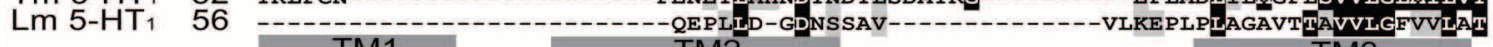

Dm 5-HT1A 241 IIGNVFVIAAIILERNLQNVANYLVASLAVADLFVACLVMPLGAVYEISQGWILGPELCDIWTSCDVLCCTAS ILHLVAT Dm 5-HT1B 105 I IGNVFVIAAIILERNLQNVANYLVA SLAVADLFVACLVMPLGAVYEI INGWI LGPELCDIWTSCDVLCCTASILHLVAI $\mathrm{Pa} 5-\mathrm{HT}_{1 \mathrm{~A}} 164$ VIGNVEVIAAILLERNLQNVANYLIVSLAVADLMVACLVMPLGAVYE ISKGWILGPELCDMWT SDVLCCTASILHLVAI Tm $5-H_{1} 132$ VIGNVFVIAAI LLERNLQNVANYLIVSLAVAD LMVACLVMPLGAVYA I SNNWIMGPELCDMWTS IDVLCCTASILHLVAI Lm 5-HT 195 VVGNVFVIAAILLERHLQNVANYLILSLAVADLIVACLVMPLGAVYEVSSOWTLGPELCDMWTASDVLCCTASILHLVAI

Dm 5-HT 1 A 321 AVDRYWAVTNIDYIHSRTSNRVFMMIFCVWTAAVIVSLAPQFG-WKDPDYLQRIE-QQKCMVSQDVS YQVFATCCTFYVP Dm 5-HT1B 185 AADRYWTVTNIDYNNLRTPRRVFLMI FCVWFAAL IVSLAPQEG-WKDPDYMKRIE-EQHCMVSQDVGYIFATCCTFYVP Pa 5-HT1A 244 AVDRYWAVTNVDYIHTRNGTRIGIMIVVVWSVALVVSLAPQFG-WKDPDYLDRINLQQRCLVSQDVAYQIFATCSTFYVP

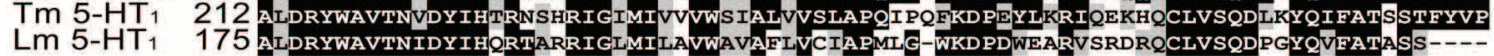

B

Dm 5-HT2B 241 VTNTSLDMFLPNLTALNTTSTASTADMATEFAVTKSFLDYSPHGYDFLFLFVVFFIFAGGLGNILVCLAVALDRKLQNVT Am 5-HT2B 69 -

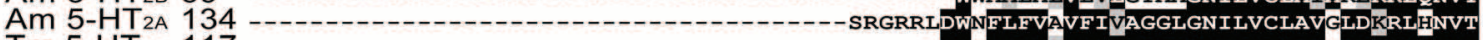
Tm 5-HT2B 117 -. $\operatorname{Lm~5-\mathrm {HT}_{2}} 1$

Dm 5-HT2B 321 NYFLFSLAIADLLVSLFVMPMGAIPAFLGYWPLGFTWCNIYVTCDVLACSSSI

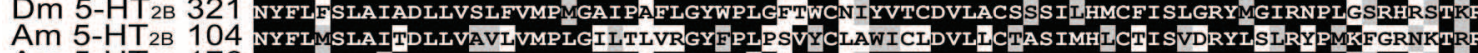
Am 5-HT2A 176 NYFLL SLAVADLLVSLFVMPLGAIPGFLGYWF GVVWCNVYVTCDVLACSAS IMHMCEISLGRYG IRNPLRTRHTSTK Tm 5-HT2B 154 NYFLLSLAIADLIVSLFVMPLGAI PGELGKWPEGVAWCTVYVTCDVLACSAS IMHMCFISLGRYLGIRNPLKTRHSTTT Lm 5-HT2 31 NYFLMSLAITDLMVAVIVMPLGILTLVTGYFPLAPVYCLAWICLDVLFCTASIMHLTTISVDRYLSLRYPMKFGRNTRR

Dm 5-HT2B 401 LTGIKIAIVWVMAMMVSSS ITVLGLVNE---KNIMPEPNICVINNRAEFVEGSLVAFYI TMMLMMVTTYALTIPLIRKKAR Am 5-HT2B 184 RVMLKISFVWVLSIAMSLPLSLMYSKED---DSVLVDGACQIP-DPLYKLIGSIICFYI PLGVMLLTYALTVRLIAKQQQ

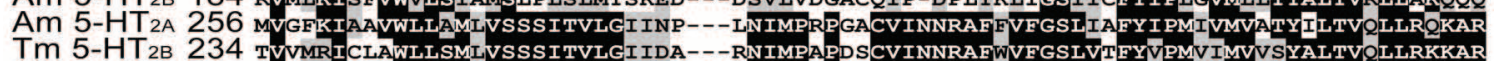

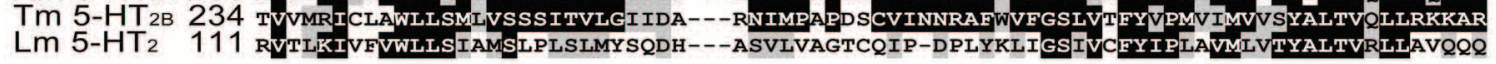

Dm 5-HT2B 478 FAA AEHPESELFRRLGGRFTLRPQHSQQQLQMFSSFSGSNNKFLSMGDGNRNFNTEGEMEEGGAPSRRSGVEPAERPLMQQ Am 5-HT2B 260 NIGGTTGWSSGWLGGPQGPSSGGLDRKTWKRFLLSKSPAGSGGTPQHTSGTSTDTELTTLDTHELWLPESEPPPSAMFA Am 5-HT2A 333 FIAEHPERDQFRRIGGRYFSTR-Tm 5-HT2B 311 FAADHPENDSS-_-_-

$\mathrm{Lm} 5-\mathrm{HT}_{2} 187$ NLCGGG-_.

c

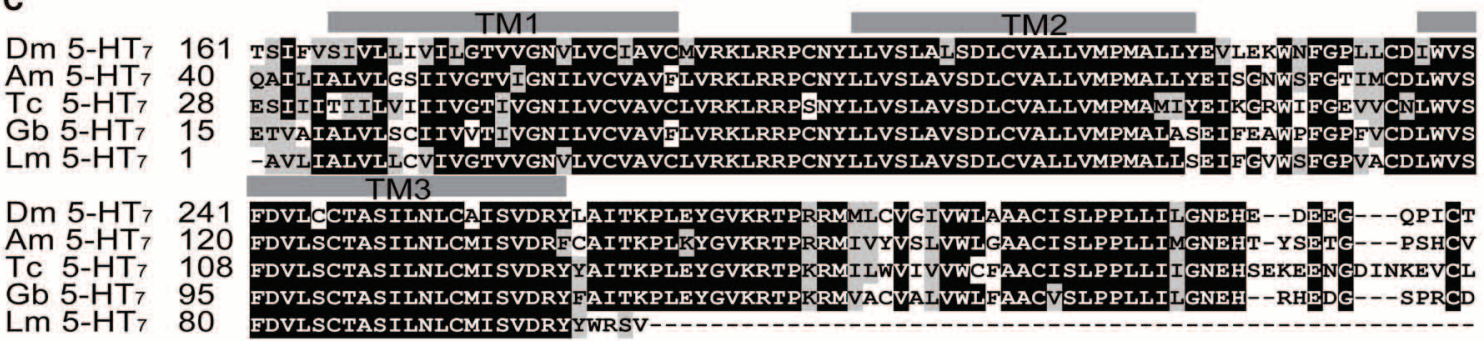

FIGURE 3 | Amino acid sequence alignment of serotonin receptors in the migratory locust and the ones in other insects. (A) Alignment of the amino acid sequences of $\mathrm{Lm} 5-\mathrm{HT}_{1}$ with orthologous receptors from Drosophila melanogaster (Dm 5-HT1A, NP_476802; Dm 5-HT1B, NP_523789), Periplaneta americana ( $\mathrm{Pa} 5-\mathrm{HT}_{1 \mathrm{~A}}, \mathrm{CAX65666)}$, and Tribolium castaneum (Tm 5- $\left.\mathrm{HT}_{1}, \mathrm{XP} \_967449\right)$. (B) Sequence alignment of $\mathrm{Lm} 5-\mathrm{HT}_{2}$ with orthologous receptors from Drosophila melanogaster (Dm 5-HT 2B, NP_730859), Apis

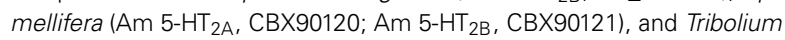

castaneum (Tc 5- $\mathrm{HT}_{2 \mathrm{~B}}, \mathrm{NP}$ _972327). (C) Sequence alignment of the $\mathrm{Lm}$ $5-\mathrm{HT}_{7}$ with orthologous receptors from Drosophila melanogaster (Dm 5- $\mathrm{HT}_{7}$, NP_524599), Apis mellifera (Am 5-HT7, CAJ28210), Tribolium castaneum (Tc 5- $\mathrm{HT}_{7}, \mathrm{XP}_{\mathbf{2}}$ 966577), and Gryllus bimaculatus (Gb 5-HT7, BAJ83482). Identical residues of the aligned sequences are shown as white letters against black ones, whereas conservatively substituted residues are shaded. Putative transmembrane regions are indicated by gray bars. Dashes indicate gaps that were introduced to maximize homology. 


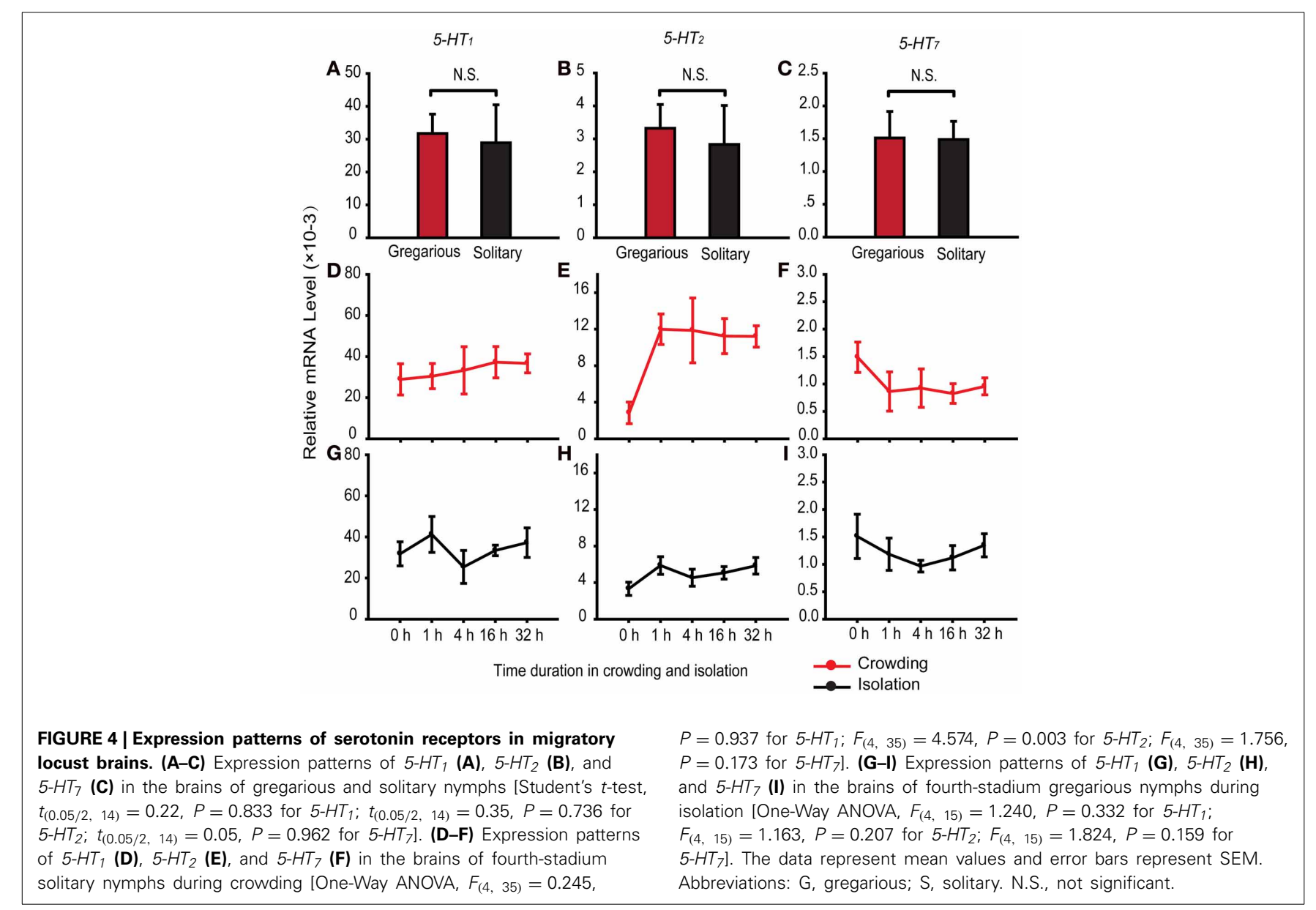

we injected $5 \mathrm{mM}$ serotonin into the gregarious nymphs and then exposed them to 15 or $30 \mathrm{~min}$ of isolation before behavioral assay. We found that the gregarious nymphs injected with serotonin followed by $15 \mathrm{~min}$ of isolation showed a significant behavioral shift toward the solitary phase state, with $50 \%$ of injected nymphs at P-sol interval of 0.8-1.0, compared with the control group (Mann-Whitney $U$-test, $U=117, P=0.024$ ) (Figure 5D). Serotonin administration with $30 \mathrm{~min}$ of isolation also resulted in a behavioral shift from the gregarious to solitary state, with $73.3 \%$ of injected solitary nymphs at P-sol interval $=$ 0.8-1.0 compared with the controls subjected to $30 \mathrm{~min}$ of isolation (Mann-Whitney $U$-test, $U=310, P=0.038$ ) (Figure 5E). Results confirmed the hypothesis that serotonin regulated the solitariness of gregarious locusts.

We inactivated serotonin receptors through pharmacological intervention to further verify whether serotonin mediated the isolation of gregarious nymphs. Injection of a antagonist cocktail (ketanserin and methiothepin) coupled with $15 \mathrm{~min}$ of isolation did not affect the behavior changes (Mann-Whitney $U$ test, $U=172, P=0.461$ ) (Figure 5F). However, the locusts treated with the antagonist cocktail in the head cavity significantly shifted their behavior from the solitary to gregarious phase after $30 \mathrm{~min}$ of isolation, with $50 \%$ of the injected ones at P-sol interval $=0.0-0.2$ (Mann-Whitney $U$-test, $U=110, P=0.014$ ) (Figure 5G). Antagonist-injected gregarious nymphs exposed to isolation for $30 \mathrm{~min}$ showed full gregarious behavior. These results indicate that interfering with serotonin receptors during isolation prevents locust solitariness.

\section{ROLE OF THE SEROTONIN RECEPTOR IN THE CROWDING OF SOLITARY NYMPHS}

Increased $5-\mathrm{HT}_{2}$ expression in the brain of locusts suggested the role of this receptor in regulating the gregariousness of locusts. To further clarify the role of serotonin receptor in regulating the gregariousness of solitary nymphs, we injected the serotonin receptor $5-\mathrm{HT}_{2}$ agonist $( \pm)$-DOI into the fourth-stadium solitary nymphs and detected the function of serotonin-5- $\mathrm{HT}_{2}$ signaling during time course crowding. We injected different $( \pm)$-DOI doses into the brain and examined the behavioral responses. Results showed that the solitary nymphs injected with $( \pm)$-DOI $(5 \mathrm{mM}$ and $10 \mathrm{mM})$ shifted toward the gregarious phase in terms of behavior traits (Mann-Whitney $U$-test, $U=199, P=0.001$ for $5 \mathrm{mM}$; $U=$ 94, $P=0.031$ for $10 \mathrm{mM}$ ) (Figures 6A-C). However, the $5 \mathrm{mM}$ $( \pm)$-DOI-injected solitary nymphs still showed solitary behavior during the time course of crowding, even after crowding $32 \mathrm{~h}$ the control group displayed significant behavioral change (Mann-Whitney $U$-test, $U=146, P=0.442$ for $1 \mathrm{~h}$; $U=647, P=0.868$ for $4 \mathrm{~h} ; U=146, P=0.103$ for $16 \mathrm{~h}$; 

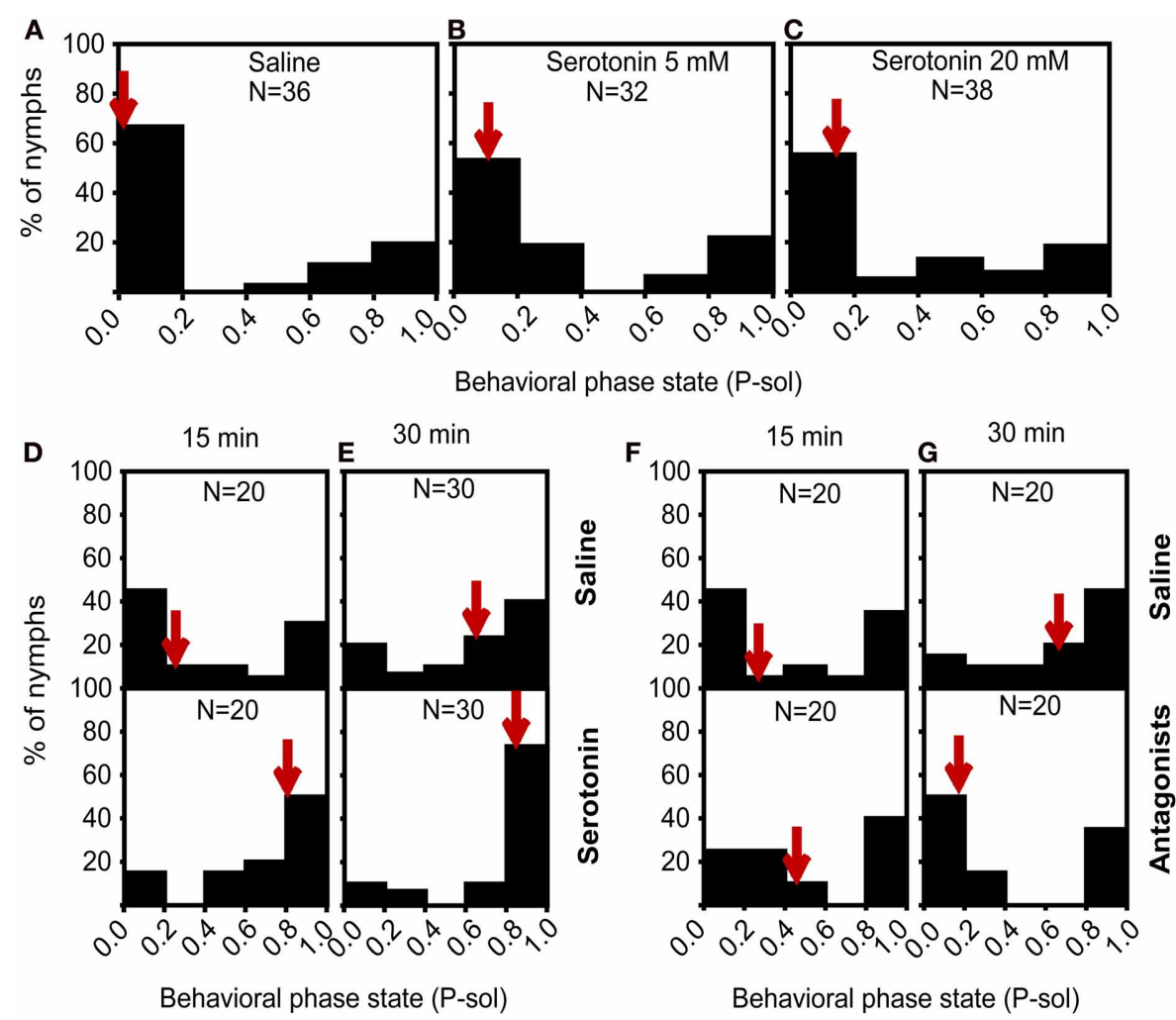

FIGURE 5 | Behavioral responses of gregarious nymphs after pharmacological intervention in serotonin signaling. (A-C) Effect of serotonin on the phase state of gregarious nymphs, saline (A), $5 \mathrm{mM}$ (B), and $20 \mathrm{mM}(\mathbf{C})$. (D,E) Effect of serotonin on the phase state of gregarious

nymphs isolated for $15 \mathrm{~min}$ (D) and $30 \mathrm{~min}$ (E). (F,G) Effects of serotonin receptor antagonists on the phase state of gregarious nymphs isolated for $15 \mathrm{~min}$ (F) and $30 \mathrm{~min}(\mathbf{G})$. P-sol is probabilistic metric of solitariness. Arrows indicate median P-sol values.

$U=334, P=0.002$ for $32 \mathrm{~h}$ ) (Figures 6D-G). Consistent with the previous study that the solitary nymphs displayed significant behavioral changes after crowding $32 \mathrm{~h}$ (Guo et al., 2011), ( \pm )-DOI injection inhibited this behavioral shift compared to the control group (Figure 6G). Therefore, activation of $5-\mathrm{HT}_{2}$ signaling inhibited gregariousness during the crowding process.

To further explore the role of $5-\mathrm{HT}_{2}$ signaling in crowding of solitary nymphs, we analyzed the effect of $5-H_{2} T_{2}$ RNAi knockdown on the behavioral state of solitary nymphs exposed to crowding. First, we tested the efficiency of RNAi knockdown using different doses of double-stranded RNA. Results showed that the $5-\mathrm{HT}_{2}$ mRNA level significantly decreased after injecting 24 or $36 \mathrm{ng}$ of dsRNA, but no change was detected in the dsGFP-injected controls and $12 \mathrm{ng}$ ds5-HT⿰亻 groups (Figure 7A). In the solitary nymphs, 5- $\mathrm{HT}_{2}$ RNAi knockdown did not affect the behavioral state (Mann-Whitney $U$ test, $U=146, P=0.149$ ) (Figure 7B). In addition, $5-H_{2}$ RNAi knockdown did not influence the behavioral state and behavioral shift of solitary nymphs compared with dsGFPinjected groups during the crowding process (Mann-Whitney $U$-test, $U=322, P=0.883$ for $1 \mathrm{~h} ; U=264, P=0.823$ for $4 \mathrm{~h} ; U=237, P=0.689$ for $16 \mathrm{~h}$; $U=181, P=0.327$ for $32 \mathrm{~h}$ ) (Figures 7C-F).

\section{DISCUSSION}

In this study, during the isolation of the gregarious nymphs, the concentration of serotonin increased significantly, whereas serotonin receptors expressed in a stable manner. The injection of serotonin in the isolated nymphs promoted the behavioral change from gregarious to solitary phase. During the crowding of solitary nymphs, the serotonin level in the brain remained unchanged, whereas $5-\mathrm{HT}_{2}$ increased after $1 \mathrm{~h}$ of crowding and showed stable expression level thereafter. Activation of $5-\mathrm{HT}_{2}$ inhibited the gregariousness of solitary nymphs in crowding treatment. Thus, serotonin promoted the phase change from gregarious to solitary phase.

\section{SEROTONIN ACCELERATES THE BEHAVIORAL CHANGE FROM GREGARIOUS TO SOLITARY PHASE DURING ISOLATION}

In this study, we verified that injection of serotonin in the brain did not induce solitariness in gregarious nymphs, but injection of serotonin did accelerate the behavioral transition to the solitary phase during isolation of gregarious nymphs. Blocking the function of serotonin by injection of serotonin receptor antagonist cocktails prevented the behavioral shift from the gregarious to solitary phase during isolation. These results suggest that increase of serotonin levels during isolation are a result of the process of gregarious nymph isolation. In addition, the 

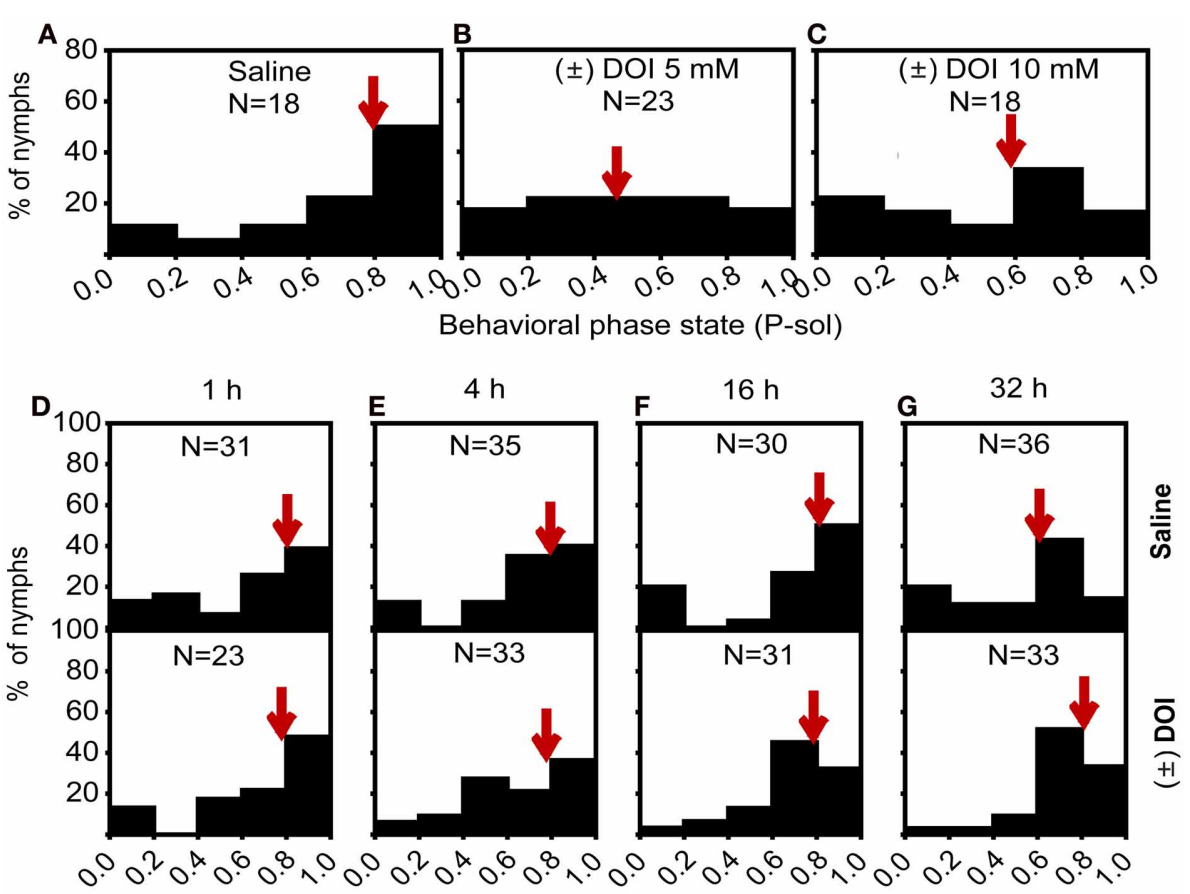

Behavioral phase state (P-sol)

FIGURE 6 | Behavioral responses of solitary nymphs after activating the $\mathbf{5}-\mathbf{H T}_{\mathbf{2}}$ signaling pathway. (A-C) Effect of $( \pm)$ DOI on the phase state of solitary nymphs, saline (A), $5 \mathrm{mM}$ (B), and $10 \mathrm{mM}$ (C). (D-G) Effect of ( \pm )
DOI on the phase state of solitary nymphs subjected to crowding for $1 \mathrm{~h}$ (D), $4 \mathrm{~h}$ (E), $16 \mathrm{~h}$ (F), and $32 \mathrm{~h}$ (G). P-sol is probabilistic metric of solitariness. Arrows indicate median P-sol values. increase in serotonin levels and the stable expression of serotonin receptors during isolation suggest that serotonin signaling mediated this process at the neurochemical level, but not through mechanisms underlying receptor expression. Consistent with our hypothesis, gregarious nymphs treated with serotonin and coupled with $30 \mathrm{~min}$ of isolation showed solitary behavior, whereas the antagonist cocktail inhibited this transition. In the isolation process, the gregarious nymphs displayed a behavioral shift from attraction to repulsion responses and their levels of movement were reduced to the level of solitary controls (Guo et al., 2011). The phase change of locusts relies on their decision to join or leave the other locusts (Uvarov, 1966; Burrows et al., 2011; Guo et al., 2011), and serotonin reportedly mediates this decision to withdraw in invertebrates and vertebrates. In crickets, serotonin has been proposed to integrate agonistic signals for the decision to flee (Stevenson and Rillich, 2012). Similarly, serotonin limits impulsivity (Nelson and Trainor, 2007) or stimulates the drive to withdraw in mammals (Tops et al., 2009). Spoont (Spoont, 1992) reviewed that the increase in serotonin decreased sensory reactivity and protected against overstimulation; thus, serotonin probably reduces the responses and activities of gregarious nymphs to extrinsic factors. In addition, the depletion of serotonin induces hyperactivity and enhances the startle responses of crickets (Stevenson et al., 2000, 2005), whereas higher doses of serotonin inhibits the locomotion behavior of the juvenile lobster Homarus americanus (Peeke et al., 2000). Therefore, serotonin may integrate the outer stimuli for the decision to withdraw and inhibit locomotion during the isolation of gregarious nymphs. The fact that serotonin did not affect the behavior of the gregarious phase suggested that other modulatory mechanisms also played important roles in the isolation process.

\section{ACTIVATION OF SEROTONIN-5-HT, SIGNALING INHIBITS THE GREGARIOUSNESS OF SOLITARY NYMPHS IN CROWDING TREATMENT}

In our previous study, we found that injection of the serotonin precursor 5-HTP coupled with long-term crowding inhibited the gregariousness (Ma et al., 2011). In this study, we only discovered a significant increase in $5-\mathrm{HT}_{2}$ expression among the three serotonin receptors during crowding. Although activation of $5-\mathrm{HT}_{2}$ in solitary nymphs partially induced gregariouslike behavior, activation of $5-\mathrm{HT}_{2}$ during crowding inhibited the performance of gregarious behavior of solitary nymphs. These results showed that activation of $5-\mathrm{HT}_{2}$ induced different modulatory effects on behavior of solitary phase locusts and their crowding process. Similar to these results, serotonin modulated crayfish lateral giant escape command neurons in two different ways. Low concentration of serotonin or high concentration of serotonin reaching gradually resulted in facilitatory effects on those neurons. However, high concentration of serotonin reaching rapidly resulted in inhibitory effect on those neurons (Teshiba et al., 2001). In addition, low doses of exogenous serotonin in juvenile lobsters did not affect motor behavior but higher doses inhibited this behavior (Peeke et al., 

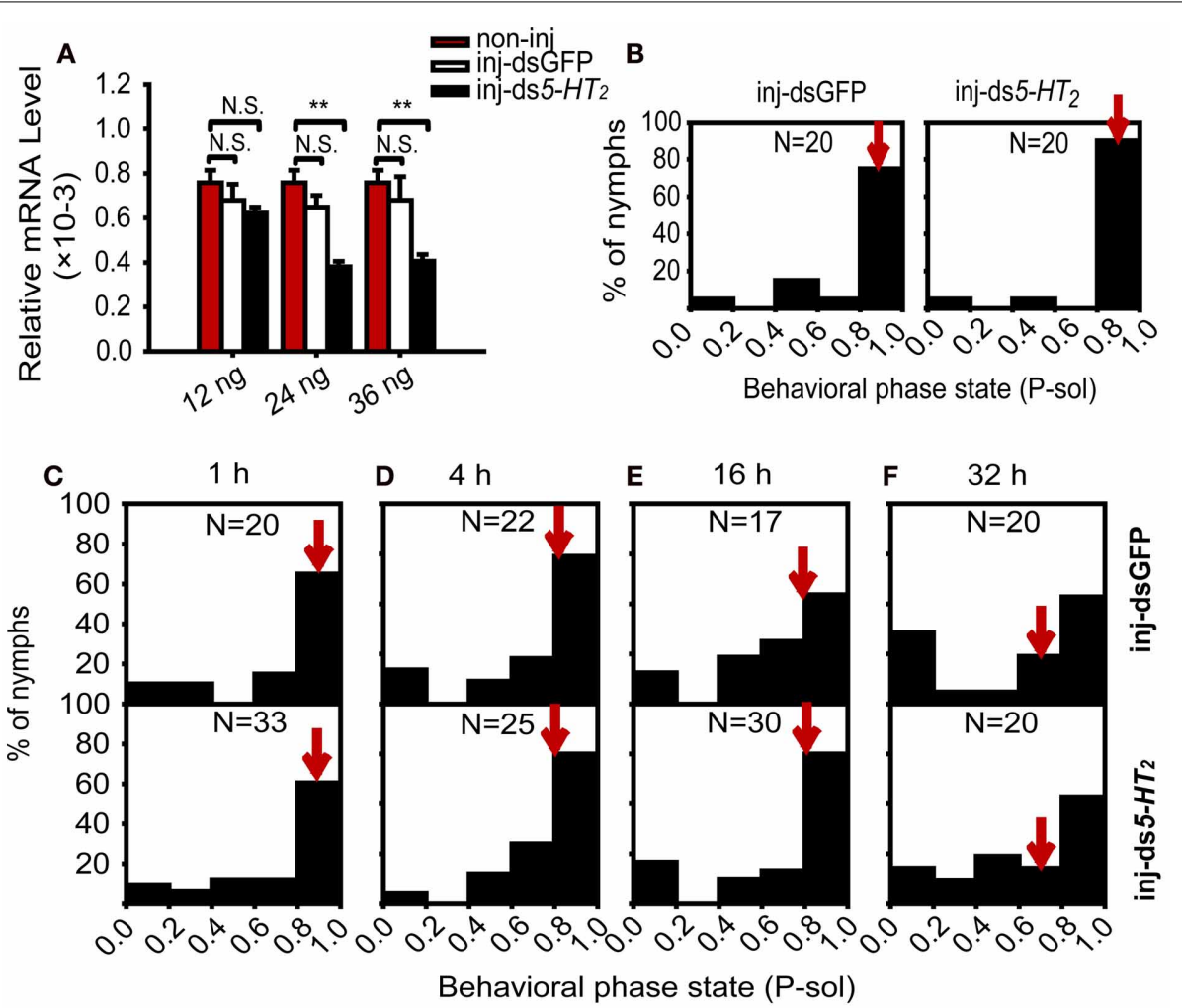

FIGURE 7 | Behavioral responses of solitary nymphs after RNAi knockdown of $\mathbf{5}-\boldsymbol{H T}_{\mathbf{2}}$. (A) Effects of RNAi on the relative mRNA level [Student's $t$-test, $t_{(0.05 / 2,14)}=1.656, P=0.129$ for $12 \mathrm{ng}$;

$t_{(0.05 / 2,14)}=6.226, P<0.001$ for $24 n g ; t_{(0.05 / 2,14)}=5.553, P<0.001$ for $36 \mathrm{ng}$. In all groups, treatment (inj-GFP, inj-ds5-HT2) compared with the corresponding non-injected controls. The data represent mean values and error bars represent SEM. (B) Behavioral responses of solitary nymphs after RNAi knockdown of 5-HT2. (C-F) Behavioral responses of solitary nymphs after RNAi knockdown of 5-HT2 with crowding for $1 \mathrm{~h}$ (C), $4 \mathrm{~h}$ (D), $16 \mathrm{~h}$ (E), and $32 \mathrm{~h}$ (F). P-sol is probabilistic metric of solitariness. Arrows indicate median $\mathrm{P}$-sol values. ${ }^{* *} P<0.01$; N.S., not significant.
2000). Thus, in solitary nymphs with low 5-HT⿰ $\mathrm{T}_{2}$ expression, $5-\mathrm{HT}_{2}$ agonist activates $5-\mathrm{HT}_{2}$ and facilitates its role in regulating behavioral change toward the gregarious phase. By contrast, with increased expression of $5-H_{2}$ during crowding, the activation of serotonin signaling pathways inhibits the phase change of solitary nymphs. Serotonin-5- $\mathrm{HT}_{2}$ signaling probably regulates phase change through dual and opposing modulatory mechanisms.

Here we found that serotonin accelerated solitariness in the isolation of gregarious nymphs. Activation of $5-\mathrm{HT}_{2}$ signaling inhibited gregariousness during the crowding of solitary nymphs. In addition, RNAi knockdown of $5-\mathrm{HT}_{2}$ did not influence the behavioral state and behavioral shift during crowding. These results indicate that the fluctuations of serotonin content and 5$H T_{2}$ expression are results of locust phase change and may be regulated by a set of differentially expressed genes or pathways involved in phase change. A previous study (Guo et al., 2011) identified a large number of differentially expressed genes related with isolation and crowding of locusts. De novo analysis of the migratory locust transcriptome revealed that many neurotransmitter receptors, synthetases, and transporters are differentially expressed between the two phases of fourth-stadium nymphs (Chen et al., 2010). The causal pathways or effectors involved in regulating phase change may result in changes in serotonin content and $5-\mathrm{HT}_{2}$ expression during the phase change of locusts.

\section{CONTROVERSIAL ROLE OF SEROTONIN IN REGULATING THE PHASE CHANGE OF MIGRATORY LOCUSTS AND DESERT LOCUSTS}

In this study, we verified that serotonin mediated solitariness and inhibited gregariousness in the phase transition of migratory locusts. This finding is contradictory to the report that serotonin initiates the swarming behavior of the desert locust (Anstey et al., 2009). The controversial role of serotonin in regulating phase change in locusts may be explained by the following explanations.

First, the role of serotonin in regulating the phase change of locusts is closely related to target tissues subjected to experimental intervention. In a study on desert locusts, the thoracic ganglia was the target for treatment with serotonin and its agonist (Anstey et al., 2009). In the present study, pharmacological intervention focused on the brain of migratory locusts. The brain of an insect integrates multisensory inputs and directs patterns of activity ascended by "lower" neural centers, such as the thoracic ganglia (Delcomyn, 1999; Schaefer and Ritzmann, 2001; Zill, 2010). Moreover, many innate behaviors such as locomotion, feeding and mating are controlled by body ganglia but not the brain (Wessnitzer and Webb, 2006). The central pattern generator 
in the thoracic ganglia of the desert locust has been identified to regulate locomotion without control by the brain (Berkowitz and Laurent, 1996). The enhancement of locomotion in the crowding of the desert locust may result from the auto-feedback loop of the central pattern generator in the thoracic ganglia of the locust. However, much more complex and important behaviors of insects are integrated through the brain (Wessnitzer and Webb, 2006). In this study, we found that serotonin regulated the solitariness of migratory locust through the intervention of serotonin signaling in the brain. In addition, the systematic application of serotonin in a recent study on desert locusts showed no influence on behavioral phase change (Tanaka and Nishide, 2012). This injection method may merge effects of serotonin in different tissues, such as thoracic ganglia and brain. Therefore, we speculated that serotonin may function via tissue-specific signaling to regulate locust phase change; however, exactly how serotonin in the brain regulates the isolation process needs further exploration. Serotonin reportedly mediates the avoidance of threat (Deakin, 2003) and the withdrawal from dangerous, averse, or highly stimulating environment (Tops et al., 2009). The increase of serotonin in the brain of the migratory locust may signal overstimulation of threats and facilitate withdrawal from the groups. Meanwhile, serotonin probably suppresses the processing of sensory input and/or interrupts the motor output to the thoracic ganglia. The behavioral shift from the gregarious to the solitary phase induced by serotonin in the brain is probably a certain adaptive response to extrinsic factors affecting the migratory locust.

Second, the duration of treatment probably resulted in contradictory effects of serotonin or agonist between the two species. In the desert locust, the short-term application of serotonin or injection of its precursor in the thoracic ganglia induced gregarious behavior (Anstey et al., 2009). In contrast, the long-term and systematic injection of serotonin had no influence on attraction/repulsion behavior, one of the important parameters indicating behavioral phase change (Tanaka and Nishide, 2012). In the migratory locust, the long-term and systematic injection of serotonin precursor inhibited the gregariousness of the migratory

\section{REFERENCES}

Anstey, M. L., Rogers, S. M., Ott, S. R., Burrows, M., and Simpson, S. J. (2009). Serotonin mediates behavioral gregarization underlying swarm formation in desert locusts. Science 323, 627-630. doi: 10.1126/science.1165939

Berg, K., and Clarke, W. (2009). "Functional selectivity at serotonin receptors," in Functional Selectivity of $G$ Protein-Coupled Receptor Ligands, ed K. Neve (Totowa, NJ: Humana Press), 155-176. doi: 10.1007/978-1-60327-335-0_9

Berkowitz, A., and Laurent, G. (1996). Central generation of grooming motor patterns and interlimb coordination in locusts. J. Neurosci. 16, 8079-8091.

locust (Ma et al., 2011). In this study, although solitary nymphs injected with serotonin receptor agonist in the brain showed partial gregarious behavior, the injection of this agonist in the brain coupled with crowding inhibited gregariousness after $32 \mathrm{~h}$ of crowding. Thus, serotonin may have a short-term auto evoking effect on outer stimuli but has no stable driving effect in the crowding of locusts.

In addition, the different performances of the conserved pathway underlying the regulation of phase change may result from the species-specific traits of the two locust species. Some regulating pathways, despite being conserved across taxa, may show differentiation between closely related species. For instance, ants and bees have an inverse relationship between foraging expression and behavior. The expression of this gene is up-regulated in honeybee foragers and down-regulated in red harvester ant foragers (Ingram et al., 2005). The serotonin pathway, which is conserved in animals, modulates phase change of migratory locusts and desert locusts (Anstey et al., 2009) through different regulating patterns. Moreover, previous studies have shown that the speed of crowding is slower than that of the isolation process in the migratory locust (Guo et al., 2011), whereas in the desert locust, the speed of crowding is quicker than that of the isolation process (Pener and Simpson, 2009). Thus, conserved molecular and neural pathways probably regulate behavioral patterns of the two locust species in a species-specific manner. The mechanism that regulates behavioral patterns of the two locust species still need to be further investigated in the future.

\section{ACKNOWLEDGMENTS}

We thank the comments and suggestions of two anonymous reviewers to improve this paper. We would like to thank Drs. Zhongsheng Sun and Chuan Ma for their expert technical assistance on this study and Chris Vavricka for his help with technical editing. This research was supported by National Natural Science Foundation of China (Nos. 31000980, 31272361 and 31210103915 ) and the National Basic Research Program of China (No. 2012CB114102).

during the development of phase traits. PLOS ONE 5:e15633. doi: 10.1371/journal.pone.0015633

Colas, J. F., Launay, J. M., Kellermann, O., Rosay, P., and Maroteaux, L. (1995). Drosophila 5- $\mathrm{HT}_{2}$ serotonin receptor - Coexpression with Fushi-Tarazu during Segmentation. Proc. Natl. Acad. Sci. U.S.A. 92, 5441-5445. doi: 10.1073/pnas.92. 12.5441

Collett, M., Despland, E., Simpson, S. J., and Krakauer, D. C. (1998). Spatial scales of desert locust gregarization. Proc. Natl. Acad. Sci. U.S.A.95, 13052-13055. doi: 10.1073/pnas.95.22.13052.

Deakin, J. F. W. (2003). Depression and antisocial personality disorder: two contrasting disorders of 5HT function. J. Neural Transm. Suppl. 64, 79-93. doi: 10.1007/978-3-70916020-6_5

Delcomyn, F. (1999). Walking robots and the central and peripheral control of locomotion in insects. Auton. Robots 7, 259-270. doi: 10.1023/A: 1008928605612

Despland, E. (2001). Role of olfactory and visual cues in the attraction/repulsion responses to conspecifics by gregarious and solitarious desert locusts. J. Insect Behav. 14, 35-46. doi: 10.1023/A:100784 5528500

Despland, E., Collett, M., and Simpson, S. J. (2000). Small-scale processes in desert locust swarm formation: how vegetation patterns influence gregarization. Oikos 88 , 
652-662. doi: 10.1034/j.1600-0706. 2000.880322.x

Guo, W., Wang, X. H., Ma, Z. Y., Xue, L. A., Han, J. Y., Yu, D., et al. (2011). CSP and Takeout genes modulate the switch between attraction and repulsion during behavioral phase change in the migratory locust. PLoS Genet. 7:e1001291. doi: 10.1371/journal.pgen.1001291

Ingram, K. K., Oefner, P., and Gordon, D. M. (2005). Task-specific expression of the foraging gene in harvester ants. Mol. Ecol. 14, 813-818. doi: 10.1111/j.1365-294X. 2005.02450.x

Johnson, O., Becnel, J., and Nichols, C. D. (2009). Serotonin 5-HT2 and 5 - $\mathrm{HT}_{1 a}$-like receptors differentially modulate aggressive behaviors in Drosophila Melanogaster. Neuroscience 158, 1292-1300. doi: 10.1016/j.neuroscience.2008.10.055

Kang, L., Chen, X. Y., Zhou, Y., Liu, B. W., Zheng, W., Li, R. Q., et al. (2004). The analysis of large-scale gene expression correlated to the phase changes of the migratory locust. Proc. Natl. Acad. Sci. U.S.A. 101, 17611-17615. doi: 10.1073/pnas.0407753101

Ma, Z. Y., Guo, W., Guo, X. J., Wang, X. H., and Kang, L. (2011). Modulation of behavioral phase changes of the migratory locust by the catecholamine metabolic pathway. Proc. Natl. Acad. Sci. U.S.A. 108, 3882-3887. doi: 10.1073/pnas. 1015098108

Moczek, A. P. (2010). Phenotypic plasticity and diversity in insects. Philos. Trans. R. Soc. B Biol. Sci. 365, 593-603. doi: 10.1098/rstb. 2009.0263

Nelson, R. J., and Trainor, B. C. (2007). Neural mechanisms of aggression. Nat. Rev. Neurosci. 8, 536-546. doi: 10.1038/nrn2174

Nichols, D. E., and Nichols, C. D. (2008). Serotonin receptors. Chem. Rev. 108, 1614-1641. doi: 10.1021/cr078224o

Peeke, H. V. S., Blank, G. S., Figler, M. H., and Chang, E. S. (2000).
Effects of exogenous serotonin on a motor behavior and shelter competition in juvenile lobsters (Homarus americanus). J. Comp. Physiol. A 186, 575-582. doi: 10.1007/s00359 0000113

Pener, M. P., and Simpson, S. J. (2009). Locust phase polyphenism: an update. Adv. Insect Physiol. 36, 1-272. doi: 10.1016/S0065-280636 001-9

Roessingh, P., Simpson, S. J., and James, S. (1993). Analysis of phaserelated changes in behaviour of desert locust nymphs. Proc. $R$. Soc. B Biol. Sci. 252, 43-49. doi: 10.1098/rspb.1993.0044

Rogers, S. M., Matheson, T., Despland, E., Dodgson, T., Burrows, M., and Simpson, S J. (2003). Mechanosensory-induced behavioural gregarization in the desert locust Schistocerca gregaria. J. Exp. Biol. 206, 3991-4002. doi: 10.1242/jeb.00648

Schaefer, P. L., and Ritzmann, R. E. (2001). Descending influences on escape behavior and motor pattern in the cockroach. J. Neurobiol. 49, 9-28. doi: 10.1002/neu.1062

Simpson, S. J., Despland, E., Hägele, B. F., and Dodgson, T. (2001) Gregarious behavior in desert locusts is evoked by touching their back legs. Proc. Natl. Acad. Sci. U.S.A. 98, 3895-3897. doi: 10.1073/ pnas.071527998

Sonnhammer, E. L., Von Heijne, G., and Krogh, A. (1998). A hidden Markov model for predicting transmembrane helices in protein sequences. Proc. Int. Conf. Intell. Syst. Mol. Biol. 6, 175-182.

Spoont, M. R. (1992). Modulatory role of serotonin in neural information-processing - implications for human psychopathology. Psychol. Bull. 112, 330-350. doi: 10.1037//0033-2909.112.2.330

Stevenson, P. A., Dyakonova, V., Rillich, J., and Schildberger, K. (2005). Octopamine and experience-dependent modulation of aggression in crickets. J. Neurosci.
25, 1431-1441. doi: 10.1523/JNEUR OSCI.4258-04.2005

Stevenson, P. A., Hofmann, H. A. Schoch, K., and Schildberger, K. (2000). The fight and flight responses of crickets depleted of biogenic amines. J. Neurobiol. 43 , 107-120. doi: 10.1002/(SICI) 1097469543，2<107::AID-NEU1>3.0.C $\mathrm{O} ; 2-\mathrm{C}$

Stevenson, P. A., and Rillich, J. (2012) The decision to fight or flee insights into underlying mechanism in crickets. Front. Neurosci. 6:118 doi: 10.3389/fnins.2012.00118

Tamura, K., Peterson, D., Peterson, N., Stecher, G., Nei, M., and Kumar, S. (2011). MEGA5: molecular evolutionary genetics analysis using maximum likelihood, evolutionary distance, and maximum parsimony methods. Mol. Biol. Evol. 28 2731-2739. doi: 10.1093/molbev/ msr121

Tanaka, S., and Nishide, Y. (2012). Behavioral phase shift in nymphs of the desert locust, Schistocerca gregaria: special attention to attraction/avoidance behaviors and the role of serotonin. J. Insect Physiol. 59, 101-112. doi: 10.1016/j.jinsphys. 2012.10.018

Tanaka, S., and Zhu, D. H. (2005) Outbreaks of the migratory locust Locusta migratoria (Orthoptera: Acrididae) and control in China. Appl. Entomol. Zoolog. 40, 257-263. doi: 10.1303/aez.2005.257

Teshiba, T., Shamsian, A., Yashar B., Yeh, S. R., Edwards, D. H., and Krasne, F. B. (2001). Dual and opposing modulatory effects of serotonin on crayfish lateral giant escape command neurons. J. Neurosci. 21, 4523-4529.

Tops, M., Russo, S., Boksem, M. A. S., and Tucker, D. M. (2009). Serotonin: modulator of a drive to withdraw. Brain Cogn. 71, 427-436. doi: 10.1016/j.bandc.2009 03.009

Uvarov, S. B. (1966). Grasshopper and Locusts. Vol. 1. Cambridge: Cambridge University Press.
Wessnitzer, J., and Webb, B. (2006). Multimodal sensory integration in insects-towards insect brain control architectures. Bioinspir. Biomim. 1, 63. doi: 10.1088/17483182/1/3/001

West-Eberhard, M. J. (2003). Developmental Plasticity and Evolution. Oxford: Oxford University Press.

Wu, R., Wu, Z. M., Wang, X. H., Yang, P. C., Yu, D., Zhao, C. X., et al. (2012). Metabolomic analysis reveals that carnitines are key regulatory metabolites in phase transition of the locusts. Proc. Natl. Acad. Sci. U.S.A. 109 3259-3263. doi: 10.1073/pnas.111 9155109

Zill, S. (2010). Invertebrate neurobiology: brain control of insect walking Curr. Biol. 20, R438-R440. doi: 10.1016/j.cub.2010.03.049

Conflict of Interest Statement: The authors declare that the research was conducted in the absence of any commercial or financial relationships that could be construed as a potential conflict of interest.

Received: 25 June 2013; accepted: 09 September 2013; published online: 07 October 2013.

Citation: Guo $X, M a Z$ and Kang $L$ (2013) Serotonin enhances solitariness in phase transition of the migratory locust. Front. Behav. Neurosci. 7:129. doi: 10.3389/fnbeh.2013.00129

This article was submitted to the journal Frontiers in Behavioral Neuroscience. Copyright () 2013 Guo, Ma and Kang. This is an open-access article distributed under the terms of the Creative Commons Attribution License (CC BY). The use, distribution or reproduction in other forums is permitted, provided the original author(s) or licensor are credited and that the original publication in this journal is cited, in accordance with accepted academic practice. No use, distribution or reproduction is permitted which does not comply with these terms. 